Acta Crystallographica Section A

Foundations of Crystallography

ISSN 0108-7673

\section{addenda and errata}

\title{
Geometrical theory of triple junctions of CSL boundaries. Erratum
}

\section{Y. Gertsman}

Pacific Northwest National Laboratory, PO Box 999, P8-16, Richland, WA 99352, USA. Correspondence e-mail: valery.guertsman@pnl.gov

Owing to a typesetter's error, Fig. 2 of the paper by Gertsman [Acta Cryst. (2001), A57, 369-377] was published with incorrect labelling. The figure is reproduced here with correct labels. Also, the misorientation referred to by the author as $\Sigma 33 b$ in the paper should be read as $\Sigma 33 c$. This is corrected in the revised Fig. 2 given here.

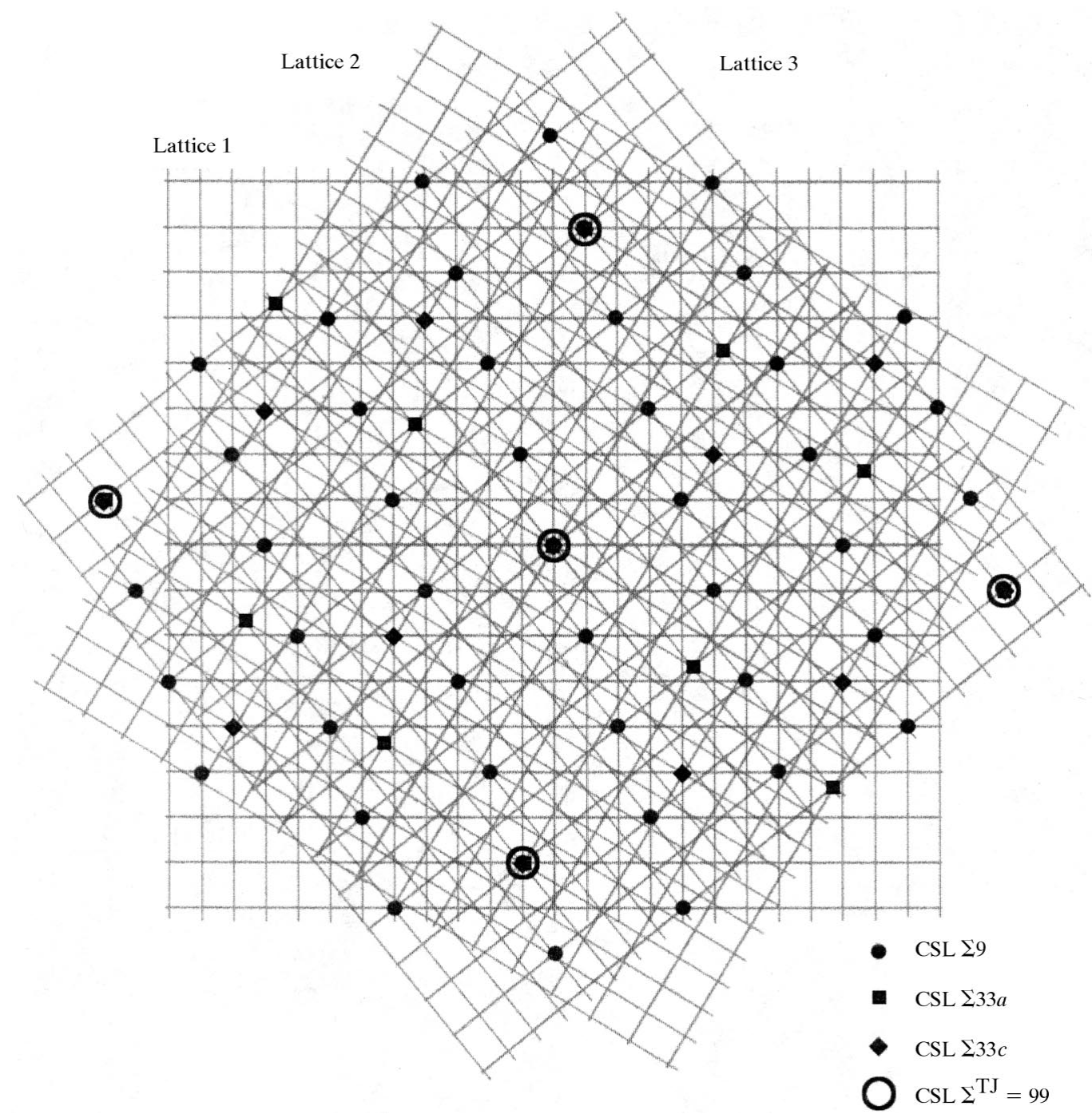

Figure 2

Superposition of three misoriented simple cubic lattices giving grain-boundary CSLs $\Sigma 9, \Sigma 33 a, \Sigma 33 c$ and triple-junction CSL with $\Sigma^{\mathrm{TJ}}=99$. The projection direction is [110]. 